\title{
Bid Is Required in NPe6-PDT-induced Apoptosis
}

\author{
Qingling Wan, Lei Liu, Da Xing* and Qun Chen \\ MOE Key Laboratory of Laser Life Science \& Institute of Laser Life Science, \\ South China Normal University, Guangzhou, China \\ Received 24 May 2007, accepted 11 October 2007, DOI: 10.1111/j.1751-1097.2007.00248.x
}

\begin{abstract}
Photodynamic therapy (PDT) employing photosensiter $\mathrm{N}$-aspartyl chlorin e6 (NPe6) can induce lysosome disruption and initiate the intrinsic apoptotic pathway. Yet the precise signal transduction pathway remains poorly understood. In this study, we have investigated the molecular mechanism in NPe6PDT-induced apoptosis in human lung adenocarcinoma cells (ASTC-a-1). A recombinant fluorescence resonance energy transfer (FRET) Bid probe was utilized to determine the kinetics of Bid cleavage. The results show that cleavage of the Bid-FRET probe occurred $150 \pm 5$ min after NPe6-PDT treatment, and this process lasted for $45 \pm 5 \mathrm{~min}$. The Bid cleavage coincided with a translocation of tBid from cytoplasm to mitochondria. Remarkably, a significant protection against cell death was observed by using small interfering RNA for Bid. Therefore, our study clearly showed the dynamics of Bid activation and redistribution during NPe6-PDT-induced apoptosis by using real-time analysis in living cells, and the inhibition of cell death by silencing Bid with interference strongly suggested that activation of Bid is required for inducing apoptosis in this experimental model.
\end{abstract}

\section{INTRODUCTION}

Photodynamic therapy (PDT) is a novel treatment modality for certain cancer and other indications. PDT employs a photosensitizer and visible light to generate singlet oxygen and other reactive oxygen species (ROS), which ultimately cause tumor destruction (1-4). The subcellular location of a photosensitizer critically influences the kinetics and the regulatory pathway activated following a PDT treatment $(5,6) . \mathrm{N}$-aspartyl chlorin e6 (NPe6), a powerful and natural occurring photosensitizer, is endowed with remarkable tumor localizing properties and in vivo antineoplastic activity upon irradiation, suggesting its clinical application as a promising PDT agent $(7,8)$. Irradiation of murine hapatoma $1 \mathrm{clc} 7$ cells preloaded with NPe6 caused lysosomal disruption, the activation of procaspase-3 and apoptosis (9-11). However, the precise cellular signal transduction mechanism in NPe6-PDT-induced apoptosis still remains poorly understood.

One mode of cell deaths caused by PDT is apoptosis (4). Apoptosis is a very important cellular event that plays a key role in pathogeny and therapy of many diseases $(12,13)$. Apoptosis

*Corresponding author email: xingda@scnu.edu.cn (Da Xing)

(c) 2007 The Authors. Journal Compilation. The American Society of Photobiology 0031-8655/08 occurs either through death receptor activation (extrinsic pathway) or mitochondrial outer membrane permeabilization (intrinsic pathway) $(14,15)$. Both pathways converge on a common "central executioner," a self-amplifying mechanism that involves mitochondrial membrane permeabilization and caspase activation cascades $(16,17)$. Despite the central role of mitochondria in apoptosis, mounting evidence suggests that other organelles, including lysosome, endoplasmic reticulum and Golgi apparatus, are also points of proapoptosis signaling integration (15). Lysosomes, which are acidic degradative organelles, have recently been implicated in the regulation of cell death (15). Lysosomal proteases translocate from the lysosomal lumen to the cytosol in response to various stimuli such as ROS $(9,18,19)$, p53 activation (20), staurosporine (21) and tumor necrosis factor- $\alpha(\mathrm{TNF}-\alpha)(22)$, and so forth.

$\mathrm{Bid}$, a member of BH3-only subgroup of Bcl-2 family, is a unique proapoptotic protein $(23,24)$. It plays an essential role in apoptotic signaling, by inducing the proapoptotic functionality of Bak and Bax, leading to cytochrome $c$ release. The $\mathrm{BH} 3$ domain of $\mathrm{Bid}$ is required for its interaction with Bax or Bak (25). It is also the target of the Bcl-2 or Bcl-xl (26). Bid is normally present in its full-length inactive form in the cytosol. Activation of Bid depends on the cleavage of intact Bid into its truncated form of $\mathrm{tBid}$. The activation of Bid can be conducted by several proteases such as caspases $(26,27)$ and calpains $(28)$. Recently, Reiners et al. (9) reported that lysosomal extracts could cleave Bid in NPe6-PDT protocols. However, the role of Bid in apoptosis induced by lysosomal disruption is not well known.

The fluorescence resonance energy transfer (FRET) technique has been used widely to study protein-protein interaction in living cells (29-34). In this study, we investigated the molecular mechanism in NPe6-PDT-induced apoptosis in ASTC-a-1cells. We utilized a recombinant Bid-FRET probe to determine the kinetics of Bid cleavage and redistribution. The role of Bid in our experimental model was determined by using small interfering RNA (siRNA) for Bid. Our data clearly show the dynamics of Bid activation and redistribution, and a significant protection against cell death was observed by silencing Bid.

\section{MATERIALS AND METHODS}

Materials. Dulbecco's modified Eagle medium (DMEM) was purchased from GIBCO (Grand Island, NY). Cell counting kit-8 (CCK-8) was purchased from Dojindo Laboratories (Kumamoto, Japan). Z-IETD-fmk (caspase-8 inhibitor) was purchased from BioVision (Mountain View, CA). Lipofectamine ${ }^{\mathrm{TM}}$ Reagent, mitochondrion- 
specific dye (MitoTracker Red) and lysosome integrity (Acridine Orange; AO) were purchased from Invitrogen (Carlsbad, CA). The photosensitizer NPe6 was a generous gift from Dr. C. Julie (Light Science Corporation). Bid-FRET and Bid-cyan fluorescent protein (CFP) were kindly supplied by Dr. K. Taira (National Institute of Advanced Industrial Science and Technology, Tsukuba, Japan) (32).

Cell culture, transfection and PDT treatment. The human lung adenocarcinoma cell line (ASTC-a-1) was obtained from the Department of Medicine, Jinan University (Guangzhou, China) and cultured in DMEM supplemented with $10 \%$ fetal calf serum, penicillin $\left(100 \mathrm{U} \mathrm{mL}^{-1}\right)$, and streptomycin $\left(100 \mu \mathrm{g} \mathrm{mL}^{-1}\right)$ in $5 \%$ $\mathrm{CO}_{2}$ at $37^{\circ} \mathrm{C}$ in a humidified incubator. Transfection was performed with Lipofectamine ${ }^{\mathrm{TM}}$ reagent according to the manufacturer's protocol. The medium was replaced with fresh culture medium after $5 \mathrm{~h}$. Cells were examined $36 \mathrm{~h}$ after transfection. Cells were coincubated with $33 \mu \mathrm{M}$ NPe 6 in the dark at $37^{\circ} \mathrm{C}$ for $10 \mathrm{~h}$. After removing the culture medium, the cells were rinsed with PBS and subsequently irradiated with a semiconductor laser (NL-FBA-2.0635; Shanghai, China) at a fluence of $4 \mathrm{~J} \mathrm{~cm}^{-2}$ (fluence rate: 10 $\mathrm{mW} \mathrm{cm}^{-2}$ ).

Confocal microscopy. Cyan fluorescent protein, MitoTracker Red, $\mathrm{NPe} 6$ and AO emissions were monitored confocally using a commercial laser scanning microscope combination system (LSM510/ConfoCor 2; Zeiss, Jena, Germany) with a Plan-Neofluar $40 \times / 1.3$ NA Oil objective. Excitation wavelength and detection filter settings for each of the fluorescent indicators were as follows: CFP fluorescence was excited at $458 \mathrm{~nm}$ with an Ar-ion laser and emission was recorded through a 470-500 nm band-pass filter. MitoTracker Red and NPe6 fluorescence was excited at $633 \mathrm{~nm}$ with a $\mathrm{He}-\mathrm{Ne}$ laser and emitted light was recorded through a $650 \mathrm{~nm}$ long-pass filter. AO fluorescence from the cells was excited at $458 \mathrm{~nm}$ with an Ar-ion laser and the emission was recorded through a $650 \mathrm{~nm}$ long-pass filter. For timecourse imaging, culture dishes were mounted onto the microscope stage equipped with a temperature-controlled chamber (Tempcontrol 37-2 digital; Zeiss).

FRET image acquisition and data analysis. Fluorescence resonance energy transfer was also performed on an LSM510 confocal microscope. To monitor the fluorescence of FRET-Bid reporter, the $458 \mathrm{~nm}$ line of an Ar-ion Laser was used to excite CFP, reflected by a dichroic mirror (main beam splitter HFT458/514). The emission fluorescence was split by a second dichroic mirror (secondary beam splitter NFT515) into separate CFP (470-500 nm band-pass) and yellow fluorescent protein (YFP; $530 \mathrm{~nm}$ long-pass) channels, respectively. The quantitative analysis of the fluorescence images was performed using Zeiss Rel 3.2 image processing software (Zeiss) by drawing regions around individual cells and obtaining the average fluorescence intensity of YFP, CFP and YFP/CFP emission ratio in each region for each image.

Cell viability assays. The human lung adenocarcinoma cell line (ASTC-a-1) cells were cultured in a 96-well microplate at a density of $5 \times 10^{3}$ cells/well for $24 \mathrm{~h}$ and then coincubated with $33 \mu \mathrm{M} \mathrm{NPe} 6$ for $10 \mathrm{~h}$ at $37^{\circ} \mathrm{C}$ in the dark. The samples were then divided into five groups and exposed to semiconductor laser irradiation at fluence of 0 , $1,2,4$ and $8 \mathrm{~J} \mathrm{~cm}^{-2}$, respectively. After the irradiation, 96-well microplates were returned to the incubator for a further culture. Cell cytotoxicity assay was assessed with a colorimetric tetrazolium saltbased assay, CCK-8. OD 450 , the absorbance value at $450 \mathrm{~nm}$, was read with a 96-well plate reader (DG5032; Huadong, Nanjing, China), to determine the viability of the cells. The viability of cells was calculated as: cell viability $(\%$ of control $)=\mathrm{OD}_{\mathrm{Tre}} / \mathrm{OD}_{\mathrm{Con}} \times 100 \%$ (where $\mathrm{OD}_{\text {Tre }}$ was the absorbance value at $450 \mathrm{~nm}$ of treated cells and $\mathrm{OD}_{\mathrm{Con}}$ was the absorbance value at $450 \mathrm{~nm}$ of control cells).

Caspase- 8 activity assay. The activity of caspase- 8 was measured using the following fluorogenic enzyme substrate IETD-AFC (Alexis Biochemicals, Coger, Paris, France). After the desired duration of different treatments, the cells were harvested at $1200 \mathrm{~g}$ and lysed with extraction buffer provided by the manufacturer. Cell lysates were centrifuged at $10000 \mathrm{~g}$ at $4^{\circ} \mathrm{C}$ for $10 \mathrm{~min}$, and the supernatants were collected. After incubation at $37^{\circ} \mathrm{C}$ for $1 \mathrm{~h}$, the samples were read in a fluorometer equipped with a $400 \mathrm{~nm}$ excitation filter and a $505 \mathrm{~nm}$ emission filter. The enzyme activity was expressed as relative fluorescence units per milligram protein of protein. The arbitrary values were presented as the mean \pm SD of four experiments.
$R N A$ interference. Bid suppression was accomplished using Bid short hairpin RNA (shRNA) constructs. To generate Bid knockdown plasmids, several annealed sets of oligonucleotides encoding shRNA corresponding to different sequences in Bid coding region were cloned individually into pGPU6/GFP/Neo vector (GenePharma, Shanghai, China). The oligonucleotides of shRNA were synthesized as follows: 1 , shBid-33: 5'-CAGCGGGATGAGGAGTGCATCACAAATTCAAGAGATTTGTGATGCACTCATCCCTTTTTTG-3'; 2, shBid-486: 5'-CACCGCGCCGTCCTTGCTCCGTGATTCAAGAGATCACGG AGCAAGGACGGCGTTTTTTG-3'. The negative control shRNA (shNC) was also generated and the oligonucleotides sequence were as follows: 5'-CACCGTTCTCCGAACGT GTCACGTCAAGAGATTACGTGACACGTTCGGAGAATTTTTTG-3'. Transient transfections with siRNA constructs were carried out using Lipofectamine ${ }^{\mathrm{TM}}$ according to the manufacturer's instruction. The transfection efficiency was $50-60 \%$.

Image processing and statistical analysis. Real-time single cell analysis was performed to study the kinetics of Bid distribution; the cells were labeled with Bid-CFP and MitoTracker Red. In each experiment, 100-300 confocal images were recorded in a time series. The images were then analyzed using Zeiss Rel3.2 image processing software. The Bid-CFP localization in mitochondria was determined based on the overlap of Bid-CFP and MitoTracker Red fluorescence images. The cells exhibiting strong punctate staining of Bid-CFP, which overlapped with the distribution of MitoTracker Red, were counted as the cells with mitochondrially localized Bid. Untreated ASTC-a-1 cells usually had very low levels of diffuse Bid-CFP staining in the cytoplasm exhibiting only low levels of mitochondrial localization. At the selected time points, the percentage of cells showing Bid distribution to mitochondria was assessed by counting the number of cells exhibiting mitochondrial Bid. Date were collected from $n=150$ 200 cells per treatment in 10-15 randomly selected image frames from three independent experiments.

Data are represented as mean \pm SEM. Statistical analysis was performed with Student's paired $t$-test. Differences were considered statistically significant at $P<0.05$.

\section{RESULTS}

\section{Localization of NPe6 in ASTC-a-1 cells}

To determine the subcellular localization of NPe6 in ASTC-a-1 cells, fluorescence images of NPe6 were acquired using the LSM confocal microscopy. NPe6 displayed a punctuated pattern of fluorescence primarily in the perinuclear area (Fig. 1, left panel). To assess whether NPe6 localizes to the lysosomes, cells were coincubated with $\mathrm{AO}$, an acidophilic dye commonly used to localize lysosomes and endosomes. AO also displayed a punctuate, perinuclear fluorescence (Fig. 1, middle panel). In the overlay image (Fig. 1, right panel), the NPe6

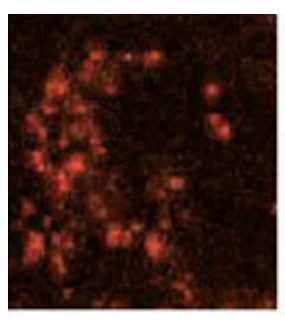

\section{NPe6}

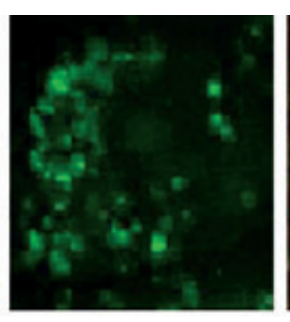

Acridine Orange

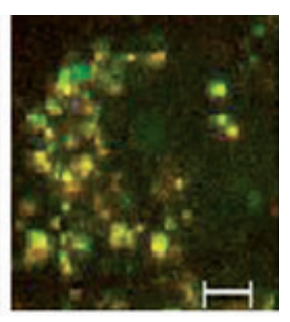

Overlay
Figure 1. Localization of NPe6 in ASTC-a-1 cells. ASTC-a-1 cells were loaded with $33 \mu \mathrm{M} \mathrm{NPe} 6$ and $0.5 \mu \mathrm{M} \mathrm{AO}$. NPe6 (left panel) and AO fluorescence (middle panel) were visualized by confocal microcopy. The overlay fluorescence image (right panel) of NPe6 and AO indicates that NPe6 is primarily localized in the lysosomes in ASTC-a-1 cells. Scale bar: $10 \mu \mathrm{m}$. 
fluorescence corresponded closely to that of AO, indicating the lysosomal localization of NPe6 in ASTC-a-1 cells.

\section{NPe6-PDT induces apoptosis in ASTC-a-1 cells}

By having established that NPe6 localized preferentially to lysosomes, we next determined a dose of PDT that would induce apoptosis. ASTC-a-1 cells were loaded with $33 \mu \mathrm{M}$ NPe6 for $10 \mathrm{~h}$ and subsequently irradiated with various light fluences. Cell viability was analyzed with CCK-8 assay. As shown in Fig. 2a, the viability of cells was obviously lower when irradiated with $4 \mathrm{~J} \mathrm{~cm}^{-2}$ and continued to decrease as the irradiation fluence increased. However, the viability did not decrease when only treated with light or NPe6. Therefore, this PDT protocol $\left(33 \mu \mathrm{M} \mathrm{NPe}, 4 \mathrm{~J} \mathrm{~cm}^{-2}\right)$ was chosen for the further experiments. The states of apoptotic cells induced by this dose of PDT were analyzed in different time as
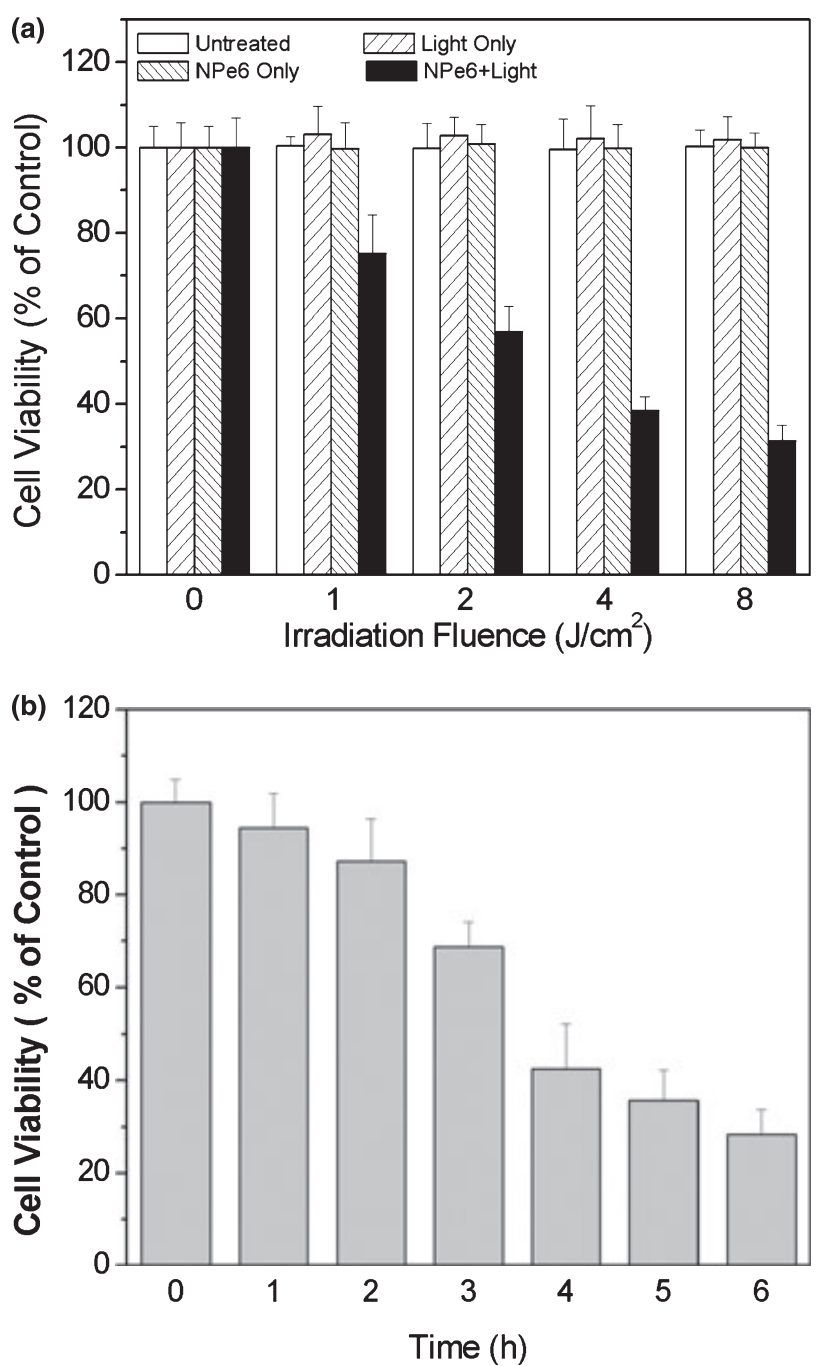

Figure 2. NPe6-PDT induces apoptosis in ASTC-a-1 cells. (a) Viability of cells irradiated at different fluences as indicated with or without $33 \mu \mathrm{M}$ NPe6 was assessed by the CCK-8 assay $6 \mathrm{~h}$ posttreatment. The data represent the mean \pm SEM of four independent experiments. (b) Viability of cells after NPe6-PDT treatment (33 $\mu \mathrm{M}$ NPe6, $4 \mathrm{~J} \mathrm{~cm}^{-2}$ ) at indicated time. The data represent the mean \pm SEM of four independent experiments. indicated. As shown in Fig. 2b, the cell viability decreased over time.

\section{Characterization of YFP-Bid-CFP in living ASTC-a-1 cells}

Activation of Bid was monitored by FRET technique following the methods of our previous study using a fusion protein YFP-Bid-CFP (31), which was constructed by connecting YFP and $\mathrm{CFP}$ to the $\mathrm{N}$ terminus and the $\mathrm{C}$ terminus of $\mathrm{Bid}$, respectively (32). At normal condition, CFP and YFP are covalently linked together, energy can be transferred directly from CFP to YFP, so fluorescence emitted from YFP can be detected when CFP is excited. Cleavage of full-length Bid results in a separation of YFP and CFP, reducing the efficiency of resonance energy transfer. Acceptor bleaching experiments
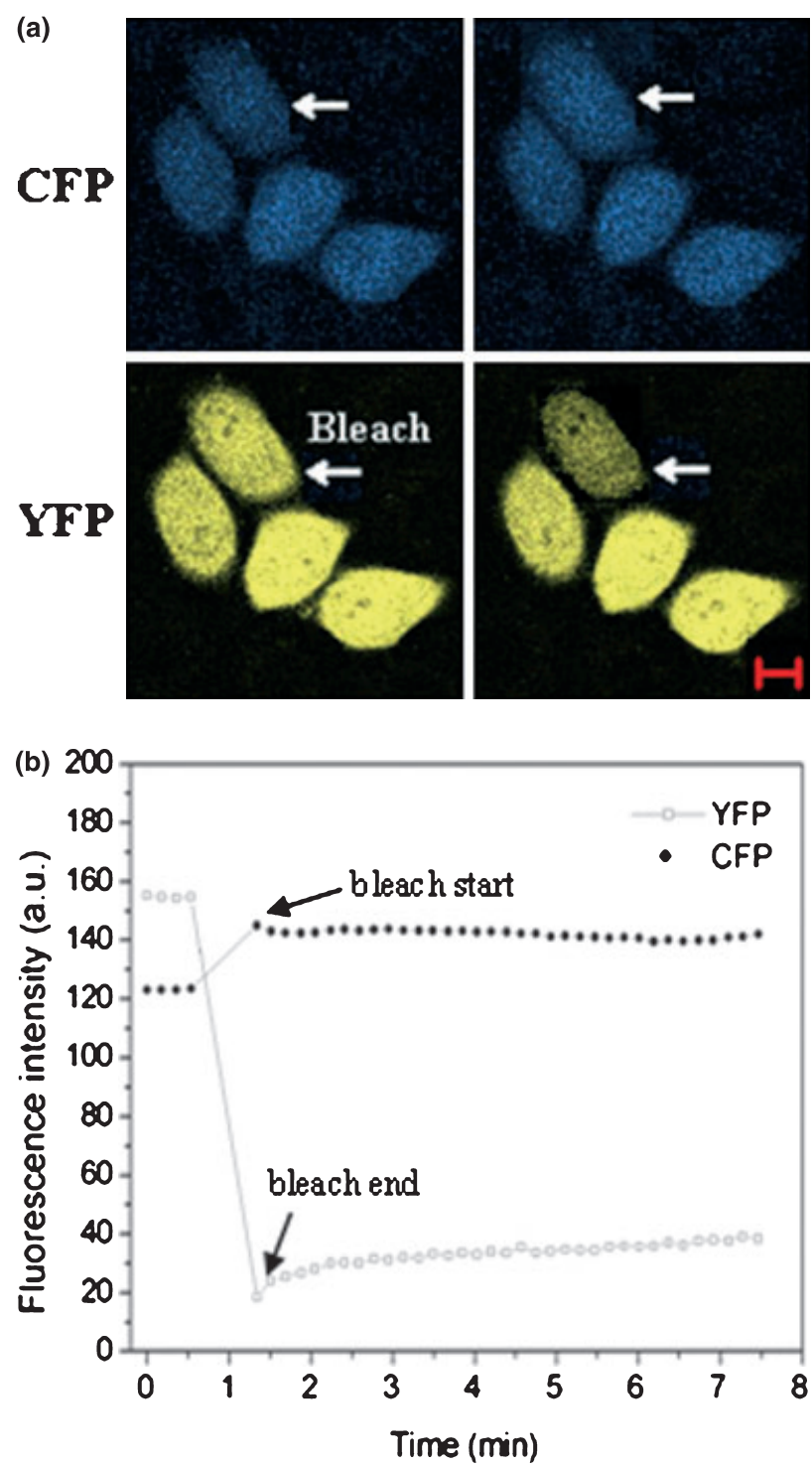

Figure 3. Characterization of Bid FRET probe in living ASTC-a-1 cells. FRET between CFP and YFP was confirmed by acceptor bleaching technique. (a) YFP was selectively bleached in a single cell by repeated scanning of the cell area at high laser power at $514 \mathrm{~nm}$. Scale bar: $10 \mu \mathrm{m}$. The experiment was repeated twice. (b) Quantitative analysis of CFP and YFP fluorescence following the bleaching of YFP. 
were carried out to assess the sensitivity of the FRET probe in our experimental system. The acceptor fluorophore YFP was selectively bleached in a single cell area by repeated scanning with a $514 \mathrm{~nm}$ laser (Fig. 3a, YFP). Upon $458 \mathrm{~nm}$ laser excitation, the level of CFP and YFP fluorescence emission was measured from the photobleached cell and plotted as a function of time (Fig. 3b). Upon bleaching there was a marked decrease in the acceptor fluorescence (YFP), which coincided with an increase in the donor fluorescence (CFP) because of an inability of the acceptor to accept energy from the donor after bleaching. Therefore, the increase of CFP fluorescence upon
YFP bleaching confirmed that FRET exists between the two fluorescent proteins in the Bid-FRET probe in living cells.

\section{FRET analysis of Bid cleavage kinetics in NPe6-PDT-induced apoptosis}

Fluorescence resonance energy transfer was used to monitor the dynamics of Bid cleavage in ASTC-a-1 cells expressing BidFRET after NPe6-PDT treatment. Figure 4a shows the FRET, CFP fluorescence emissions and FRET/CFP ratio. The intensity of CFP increased with time while that of FRET (a)

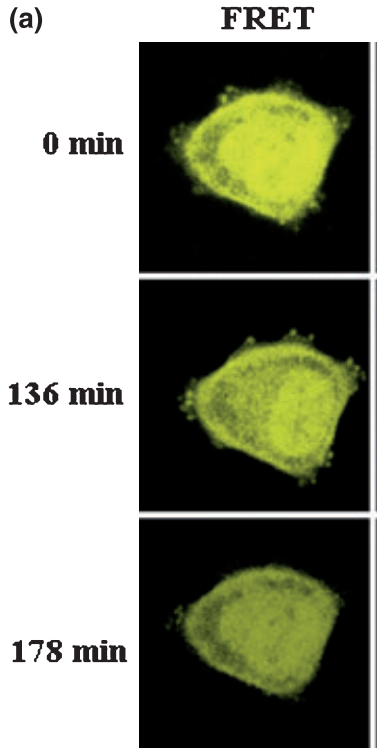

CFP

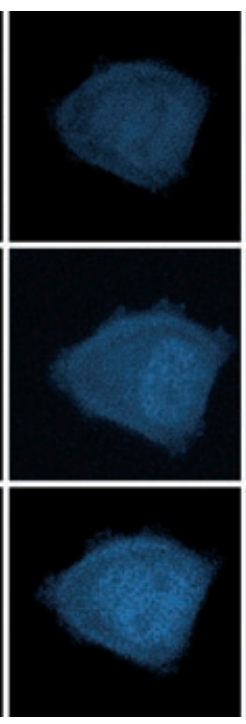

FRET/CFP

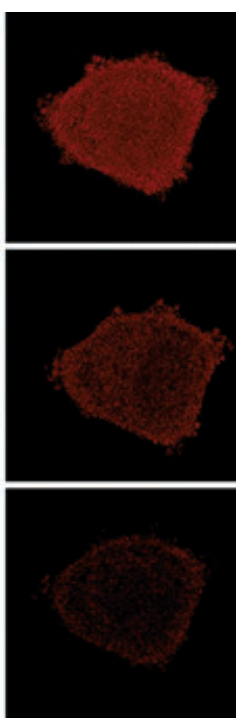

(b)

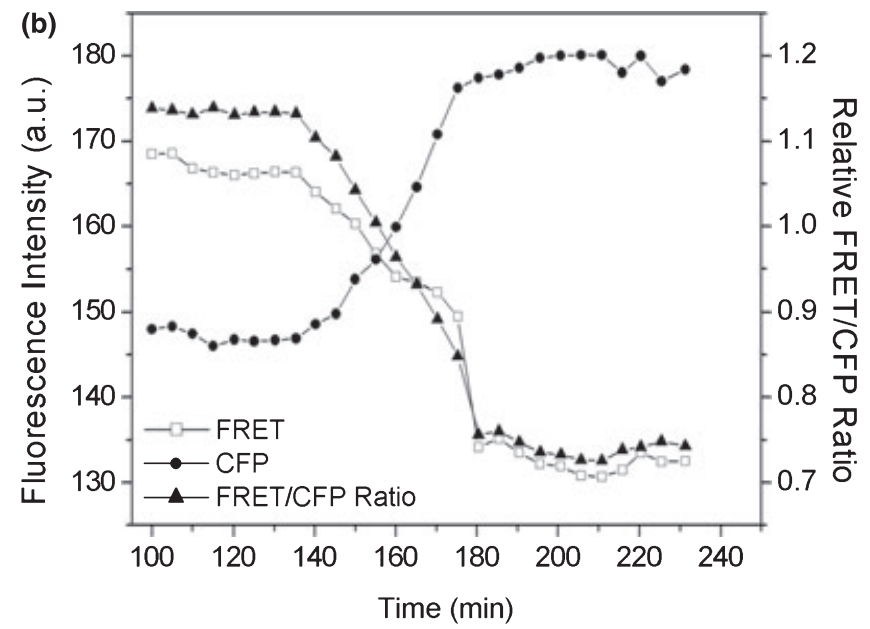

(d)
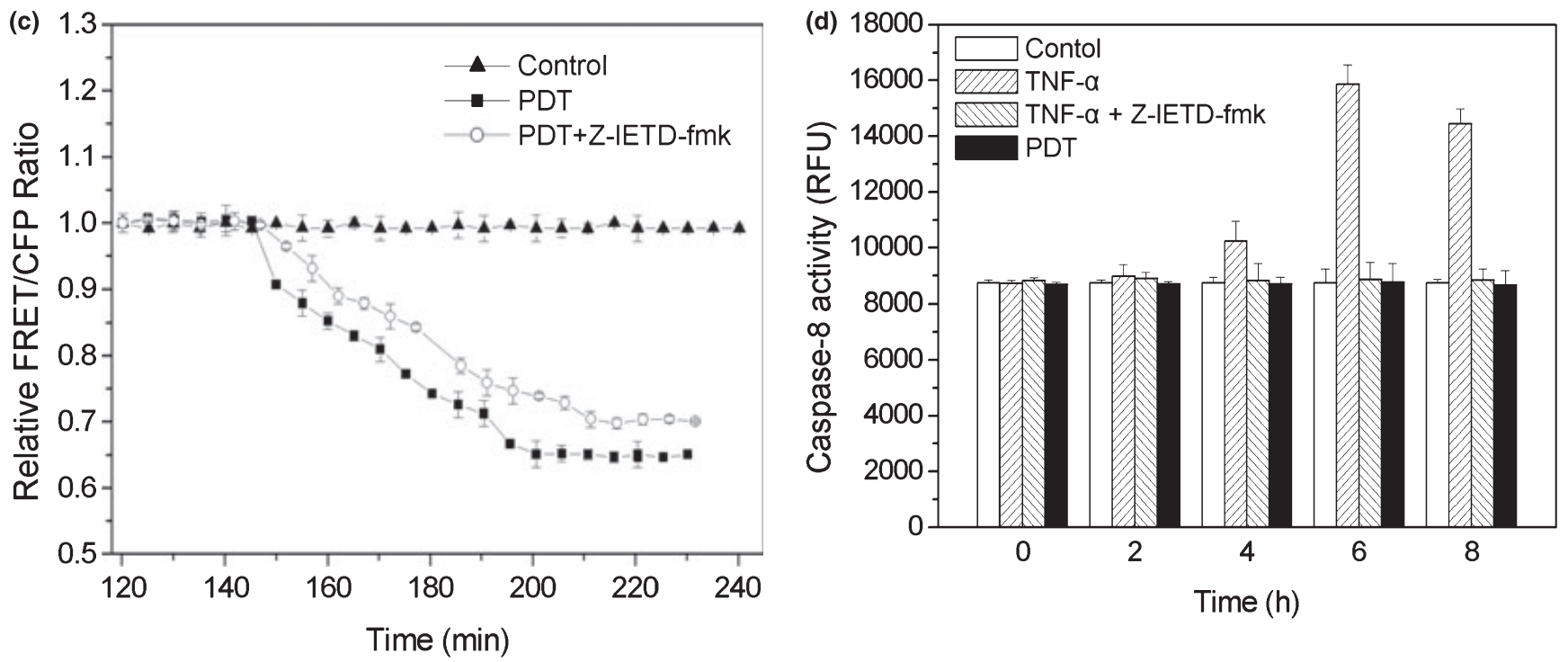

Figure 4. Dynamics detection of Bid cleavage during NPe6-PDT-induced apoptosis in living cells. (a) Fluorescence image series of FRET and CFP emission in ASTC-a-1 cells transfected with FRET-Bid after NPe6-PDT treatment. The panels of FRET, CFP and FRET/CFP are shown separately. Scale bar: $10 \mu \mathrm{m}$. (b) Dynamics of FRET, CFP emission intensities and FRET/CFP ratio after NPe6-PDT treatment. (c) Dynamics of FRET/CFP ratio after different treatments as indicated. Caspase-8 inhibitor Z-IETD-fmk (10 $\mu \mathrm{M})$ was added $1 \mathrm{~h}$ before PDT treatment and kept in the medium throughout the experimental process. The data represent the mean \pm SEM of three independent experiments. The FRET/CFP ratio at the first time point is normalized to 1 . The FRET/CFP ratio in experiments using untreated transfected cells verifies that the experimental settings were stable and reliable. (d) Caspase- 8 activity was measured by assessing the fluorometric cleavage of IETD-AFC after treatment with NPe6-PDT. The experiment with TNF- $\alpha$ treatment verifies that $10 \mu \mathrm{M}$ Z-IETD-fmk is sufficient to abrogate caspase-8 activation in treated ASTC-a-1 cells. The data represent the mean \pm SEM of four independent experiments. 
decreased after PDT treatment. The ratio of FRET to CFP fluorescence emission started decreasing about $150 \mathrm{~min}$ after treatment, as shown in Fig. $4 \mathrm{~b}$ and c. The decrease of the FRET/CFP ratio indicated that Bid was cleaved.

To determine whether Bid activation induced by NPe6-PDT was a caspase-8-dependent event, cells were pretreated with caspase- 8 selective inhibitor Z-IETD-fmk for $1 \mathrm{~h}$ before PDT treatment. In the presence of Z-IETD-fmk, the ratio FRET/CFP was the same as that of NPe6-PDT treated cells, indicating that Z-IETD-fmk did not block Bid activation (Fig. 4c). And the enzymatic assay for caspase- 8 activity also demonstrated that caspase- 8 was not activated (Fig. $4 d$ ). The results indicate that the Bid cleavage in our experimental model was caspase- 8 independent.

\section{Real-time detection of Bid redistribution induced by NPe6-PDT}

To monitor the dynamics of Bid redistribution after being cleaved by PDT treatment in ASTC-a-1 cells, Bid-CFP fluorescence image was used to monitor the Bid migration. Cells were loaded with MitoTracker Red to label the mitochondria. The typical images of real-time distribution of Bid-CFP in control nonapoptotic cells are shown in Fig. 5a. Bid-CFP has a diffuse distribution throughout the cytoplasm, with little or no evident association with mitochondria. Figure $5 \mathrm{~b}$ shows typical spatial and temporal relationships of Bid-CFP and MitoTracker Red after a PDT treatment. BidCFP translocated to mitochondria from cytoplasm as revealed by the overlaps of the Bid-CFP and MitoTracker Red fluorescence images. Quantitative analysis of time-dependent redistribution of Bid-CFP confirmed these findings (Fig. 5c).

\section{Suppressing Bid blocks cell death induced by NPe6-PDT}

To determine whether Bid is a key mediator in NPe6-PDTinduced apoptosis, siRNA technique was used to suppress the expression of Bid protein. Four shRNAs constructs, including shBid-33, shBid-486, shBid-196 and shBid-160 were designed. The data show that shBid-33 and shBid-486 obviously suppressed the expression of Bid protein compared with negative control shNC, whereas shBid-196 and shBid-160 had less effect (Fig. 6a and b). The morphology of cells expressing shNC, shBid-33 and shBid-486 after NPe6-PDT treatment was observed using LSM confocal microscopy Fig. 7a. The fourth panel shows the typical hallmarks of

Figure 5. Dynamics of Bid translocation to mitochondria during NPe6-PDT-induced apoptosis in single living cell. ( $a$ and b) Typical time-course confocal images of living ASTC-a-1 cells labeled with BidCFP and MitoTracker Red under different treatment conditions. The two panels of Bid-CFP and MitoTracker Red are shown separately and are merged to show the overlay. Bid-CFP localization at mitochondria was determined based on the overlap of Bid-CFP and MitoTracker Red fluorescence images. (a) Control cells only treated with light or NPe6 without Bid translocation over time. (b) Time-lapse images of Bid-CFP translocation after NPe6-PDT treatment. Scale bar: $10 \mu \mathrm{m}$. (c) Quantification of cells showing mitochondrial BidCFP. At indicated time points, the percentage of cells showing Bid translocation to mitochondria was assessed by counting the number of cells exhibiting mitochondrial Bid. Data were collected from 150 to 200 cells per treatment in 10-15 randomly selected image frames from three independent experiments. Data represent the mean \pm SEM. apoptosis after NPe6-PDT treatment for $6 \mathrm{~h}$. However, a significant protection against cell death was observed in cells expressing shBid-33 and shBid-486 (Fig. 7a, the sixth and
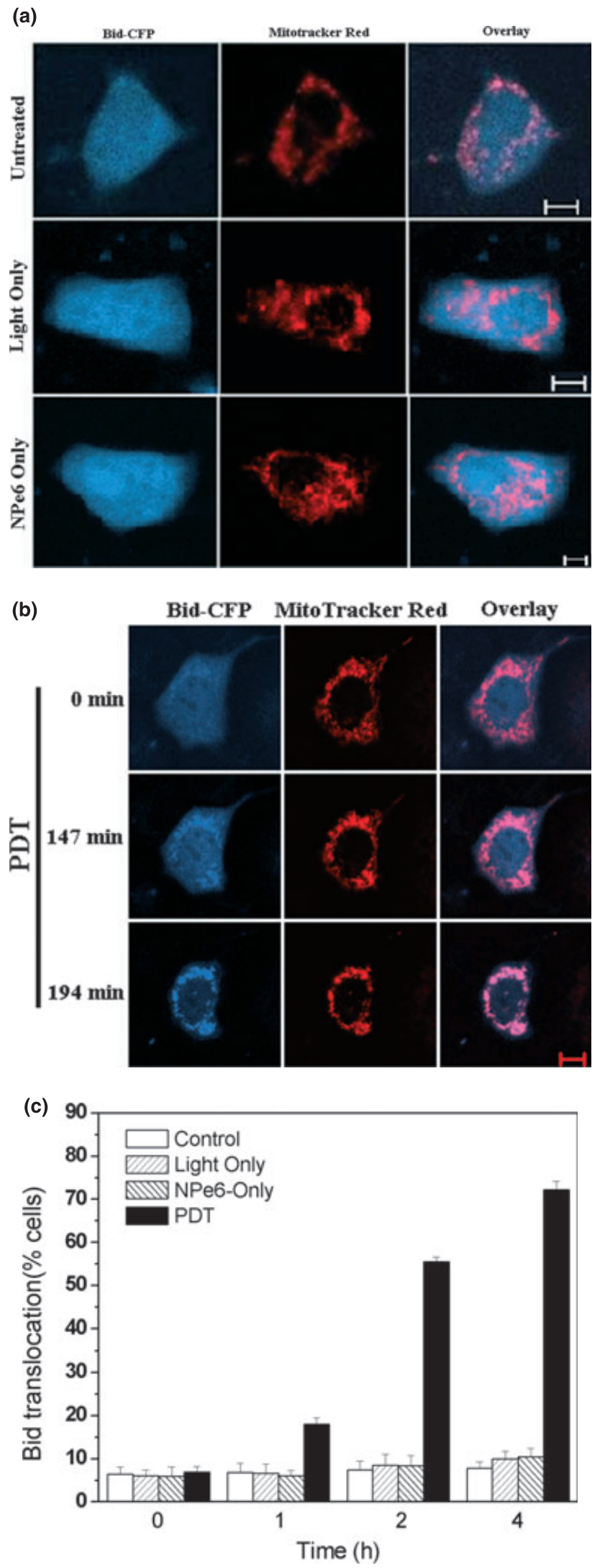
seventh panel, and Fig. 7b). These data demonstrate that Bid plays an important role in NPe6-PDT-induced apoptosis in ASTC-a-1 cells.

\section{DISCUSSION}

Apoptosis has been found to be a prominent form of cell death in response to PDT for many cells in culture, evidenced by assays measuring either the fragmentation of DNA or the condensation of chromatin (3,4,35). PDT inflicts damage to cells largely via ROS. The ROS travel only about several tens of nanometers before reacting with a molecule $(5,36)$. It is clear that the subcellular localization of the photosensitizer coincides with the primary site of photodamage. Furthermore, local photodamage to specific subcellular targets influences the kinetics and regulatory pathways activated by PDT $(5,6,37)$. It has been reported that NPe6 was a novel powerful photosensitizer. It is preferentially accumulated in lysosomes and causes lysosomal disruption after irradiation and results in apoptosis $(9,38)$. However, the cellular signaling from lysosomal disruption leading to the execution-phase characteristics of apoptosis should be further explored.

Bid, which was first reported in 1996 and is widely expressed in various tissues, plays an essential role in apoptosis (23). It

(a)
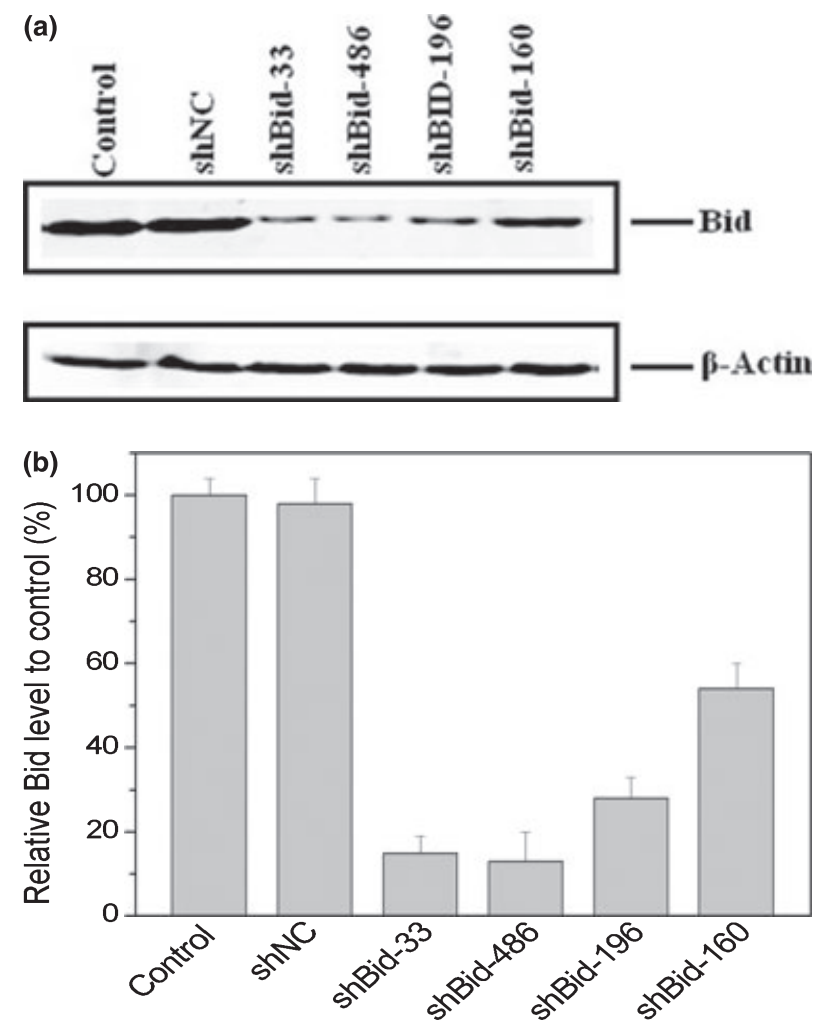

Figure 6. Suppressing Bid using siRNA in ASTC-a-1 cells. (a) ASTC-a-1 cells were transfected with the same amount of shBid-33, shBid-486, shBid-196 and shBid-160 and cultured for $36 \mathrm{~h}$. The levels of endogenous Bid were assessed by immunoblotting. ShNC was a negative control for shRNA. $\beta$-Actin served as a loading control. (b) Interference effects of shRNAs on Bid expression. The amounts of Bid in the culture medium were assayed $36 \mathrm{~h}$ after transfection. Densitometric results presented as mean \pm SD are obtained from three separate blots and plotted as a percentage of the control level. (a)
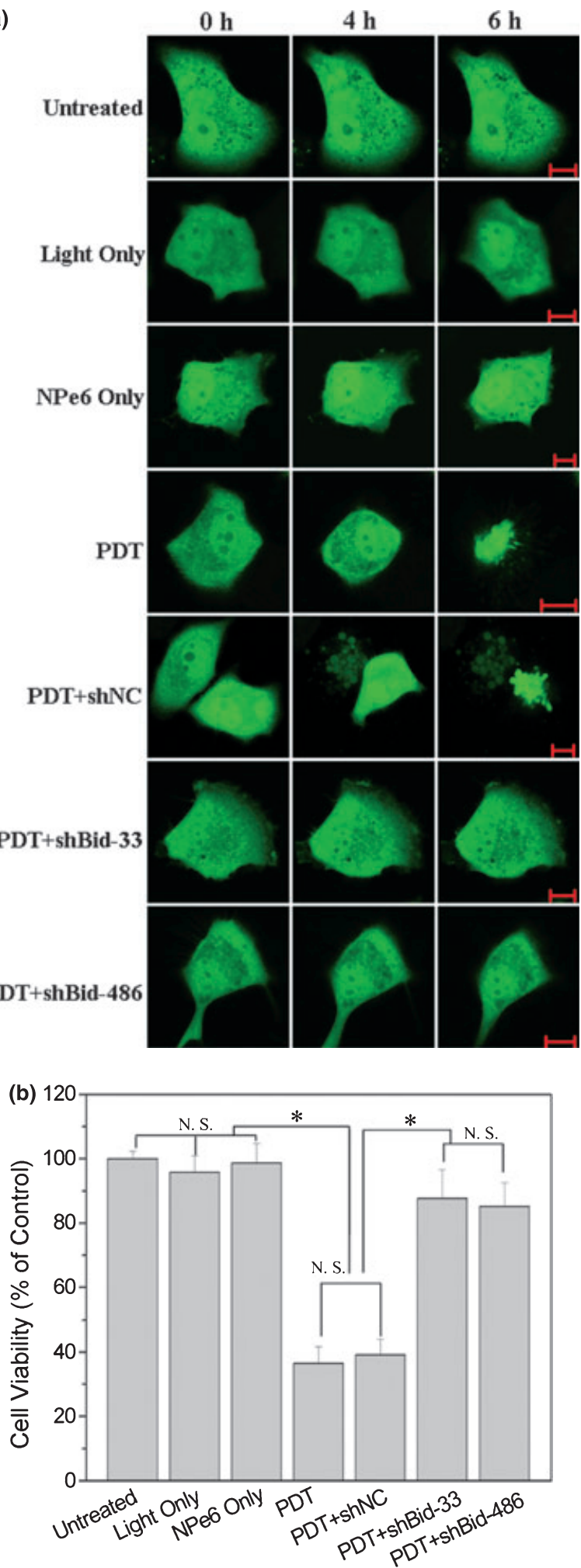

Figure 7. Suppressing Bid inhibits NPe6-PDT-induced cell death in ASTC-a-1 cells. (a) Typical time-course confocal images of ASTC-a-1 cells after different treatments as indicated. Scale bar: $10 \mu \mathrm{m}$. (b) Viability of cells after different treatments as indicated. The viability of cells was assessed by the CCK-8 assay $6 \mathrm{~h}$ post-treatment. Data represent the mean \pm SEM of four independent experiments, $P$-values for significantly different pairwise comparisons were indicated ( ${ }^{*} P<0.05 ;$ N.S., not significant). 
has been established that Bid serves the unique function of interconnecting the extrinsic death receptors for TNF- $\alpha$ and Fas to the mitochondrial amplification loop of the intrinsic pathway $(24,27)$. However, the role of $\mathrm{Bid}$ in apoptosis induced by lysosomal disruption is still controversial. Reiners et al. $(9,10)$ reported that Bid cleavage contributed to cytochrome $c$ release and procaspase-3 activation in lysosomal photodamage model of apoptosis in hepatoma cell line $1 \mathrm{c} 1 \mathrm{c} 7$. The results are consistent with that by Cirman et al. $(39,40)$ who reported that lysosomal proteases cause cytochrome $c$ release from mitochondria through Bid cleavage. These evidences suggest that Bid may be an important mediator of apoptosis. Nevertheless, Bid does not contribute to apoptosis induced by the lysosomotropic photosensitizers ciprofloxacin or norfloxacin, as Bid-deficient mouse embryonic fibroblasts are not protected against mitochondrial membrane permeabilization (41). Moreover, a study employing a model of cystatin $\mathrm{B} / \mathrm{Bid}$ double knockout mice shows that the absence of Bid did not rescue the neurological phenotype caused by constitutional activation of cathepsins (42). In the present study, we observed the dynamics of Bid activation and redistribution using realtime analysis in NPe6-PDT-induced apoptosis. To evaluate the role of Bid in our experimental model, we employed siRNA technology to highly suppress the expression of Bid protein (Fig. 6a and b). The results show that the suppressing of Bid significantly inhibited apoptosis caused by NPe6-PDT treatment (Fig. 7).

During death receptor-mediated apoptosis, Bid is known to be cleaved by caspase- 8 . Reiners et al. (9) reported that caspase- 8 unlikely contributed to Bid cleavage in NPe6-PDT protocol and TNF- $\alpha$ treatment in murine hapatoma $1 \mathrm{c} 1 \mathrm{c} 7$ cells (43). In NPe6-PDT protocol, the elevations of caspase-8 activity occurred after caspase- 3 activation and Bid cleavage (9). In the absence of FADD in murine hapatoma 1c1c7 cells, proca-caspase- 8 was not activated in response to TNF- $\alpha$ (43). Similarly, in our study Z-IETD-fmk did not block Bid activation, demonstrating that caspase- 8 did not contribute to Bid cleavage in NPe6-PDT treatment (Fig. 4c). Lysosomal extracts and some cathepsins are able to Bid activation in several cell types following lysosomal disruption $(9,39,40)$. However, which specific lysosomal protease(s) is responsible for Bid cleavage is not yet clear. Interestingly, though caspase-8 was not activated in our experimental model (Fig. 4d), compared with the results treated with NPe6-PDT, the addition of Z-IETD-fmk slightly increased the relative FRET/CFP ratio. The mechanism for this event is not clear; maybe the Z-IETD-fmk affect the intracellular physiological condition related to Bid activation. Further studies are needed to elucidate the mechanism.

Emerging experimental evidences have implicated that lysosomes play an important role in apoptosis. In the case of $\mathrm{TNF}-\alpha$, several investigators have reported that the cytokine stimulates the release of lysosomal protease into the cytosol. The induction of apoptosis by TNF- $\alpha$ has been suppressed by pharmacological and molecular modulation of lysosomal function or stability (22). In $\mathrm{H}_{2} \mathrm{O}_{2}$-induced apoptosis, lysosomal disruption occurred quickly and preceded cytochrome $c$ release and loss of $\Delta \Psi \mathrm{m}$ (19). In staurosporinetreated $\mathrm{T}$ lymphocytes, cathepsins $\mathrm{D}$ triggers Bax activation, resulting in selective apoptosis-inducing factor relocation (21). Recent studies reported that PDT employing the lysosomal photosensiter NPe6 can induce lysosome disruption and initiate the intrinsic apoptotic pathway $(9,11)$. In our study, we showed that photosensitizer NPe6 preferentially localized to the lysosomes in ASTC-a-1 cells (Fig. 1), it induced Bid activation after a PDT treatment (Figs. 4 and 5), then activated the downstream apoptotic cascades, hence leading to cell death.

FRET, a powerful technique, can spatio-temporally monitor cellular events in different physiological conditions at a single cellular level $(44,45)$. It has been utilized to study enzyme activity, protein location, protein translocation, small ligand binding, protein-protein interaction, conformational change and post-translational modification. This cannot be fully elucidated by traditional biophysical or biochemical approaches that only measure the average behavior of cell populations and the static spatial information available from fixed cells and thus, cannot provide direct access to cells' life events in their natural environment (30). In the present study, we employed FRET technique to monitor the dynamics of Bid cleavage after NPe6-PDT treatment. The results clearly show the spatial and temporal changes of Bid.

In conclusion, we have demonstrated that the activation of Bid is required in NPe6-PDT-induced apoptosis in ASTCa-1 cells. Silencing of Bid could remarkably inhibit cell death, suggesting that activation of $\mathrm{Bid}$ is required for inducing apoptosis in this experimental model. At the same time, we also monitored the dynamics of Bid activation and redistribution in this model using real-time analysis in living cells. The results show that Bid cleavage occurred $150 \pm 5$ min after NPe6-PDT treatment, which coincided with a translocation of tBid from cytoplasm to mitochondria. Our findings specifically contributed to an improved understanding of the molecular mechanisms in NPe6-PDT treatment.

Acknowledgements-We thank Dr. C. Julie of Light Science Corporation for providing photosensitizer NPe6. We thank Dr. K. Taira (National Institute of Advanced Industrial Science and Technology, Tsukuba, Japan) for providing FRET-Bid and Bid-CFP plasmids. This research study was supported by the National Natural Science Foundation of China (30470494, 30627003 and 60678050) and the Natural Science Foundation of Guangdong Province (015012).

\section{REFERENCES}

1. Dougherty, T. J., C. J. Gomer, B. W. Henderson, G. Jori, D. Kessel and M. Korbelik (1998) Photodynamic therapy: Review. J. Natl Cancer Inst. 90, 889-905.

2. Henderson, B. W. and T. J. Dougherty (1992) How does photodynamic therapy work? Photochem. Photobiol. 55, 145-157.

3. Agarwal, M. L., M. E. Clay, E. J. Harvey, H. H. Evans, A. R. Antunez and N. L. Oleinick (1991) Photodynamic therapy induces rapid cell death by apoptosis in $L 5178 Y$ mouse lymphoma cells. Cancer Res. 51, 5993-5996.

4. Oleinick, N. L., R. L. Morris and I. Belichenko (2002) The role of apoptosis in response to photodynamic therapy what, where, why, and how. Photochem. Photobiol. Sci. 1, 1-21.

5. Kessel, D., Y. Luo, Y. Deng and C. K. Chang (1997) The role of sub-cellular localization in initiation of apoptosis by photodynamic therapy. Photochem. Photobiol. 65, 422-426.

6. Oleinick, N. L. and H. H. Evans (1998) The photobiology of photodynamic therapy: Cellular targets and mechanisms. Radiat. Res. 150, 146-156. 
7. Usuda, J., H. Kato, T. Okunaka, K. Furukawa, H. Tsutsui, K. Yamada, Y. Suga, H. Honda, Y. Nagatsuka, T. Ohira, M. Tsuboi and T. Hirana (2006) Photodynamic therapy (PDT) for lung cancers. J. Thorac. Oncol. 5, 489-493.

8. Kaneko, T., H. Chiba, T. Yasuda and K. Kusama (2004) Detection of photodynamic therapy-induced early apoptosis in human salivary gland tumor cells in vitro and in a mouse tumor model. Oral Oncol. 40, 787-792.

9. Reiners, J. J. Jr, J. A. Caruso, P. Mathieu, B. Chelladurai, X. M. Yin and D. Kessel (2002) Release of cytochrome c and activation of pro-caspase-9 following lysosomal photodamage involves Bid cleavage. Cell Death Differ. 9, 934-944.

10. Caruso, J. A., P. A. Mathieu, A. Joiakim, B. Leeson, D. Kessel, B. F. Sloane and J. J. Reiners Jr (2004) Differential susceptibilities of murine hepatoma $1 \mathrm{clc} 7$ and Tao cells to the lysosomal photosensitizer NPe6: Influence of aryl hydrocarbon receptor on lysosomal fragility and protease contents. Mol. Pharmacol. 65, $1016-1028$.

11. Caruso, J. A., P. A. Mathieu and J. J. Reiners Jr (2005) Sphingomyelins suppress the targeted disruption of lysosomes/endosomes by the photosensitizer NPe6 during photodynamic therapy. Biochem. J. 392, 325-334.

12. Ashkenazi, A. and V. M. Dixit (1998) Death receptors: Signaling and modulation. Science 281, 1305-1308.

13. Nagata, S. (1997) Apoptosis by death factor. Cell 88, 355-365.

14. Danial, N. N. and S. J. Korsmeyer (2004) Cell death: Critical control points. Cell 116, 205-219.

15. Ferri, K. F. and G. Kroemer (2001) Organelle-specific initiation of cell death pathways. Nat. Cell Biol. 3, 255-263.

16. Green, D. and G. Kroemer (1998) The central executioners of apoptosis: Caspases or mitochondria? Trends Cell Biol. 8, 267271.

17. Finkel, E. (2001) The mitochondria: Is it central to apoptosis? Science 292, 624-626.

18. Roberg, K., U. Johansson and K. Ollinger (1999) Lysosomal release of cathepsin D precedes relocation of cytochrome $\mathrm{c}$ and loss of mitochondrial transmembrane potential during apoptosis induced by oxidative stress. Free Radic. Biol. Med. 27, 12281237.

19. Antunes, F., E. Cadenas and U. T. Brunk (2001) Apoptosis induced by exposure to a low steady-state concentration of hydrogen peroxide is a consequence of lysosomal rupture. Biochem. J. 356, 549-555.

20. Yuan, X. M., W. Li, H. Dalen, J. Lotem, R. Kama, L. Sachs and U. T. Brunk (2002) Lysosomal destabilization in p53-induced apoptosis. Proc. Natl Acad. Sci. USA 99, 6286-6291.

21. Bidere, N., H. K. Lorenzo, S. Carmona, M. Laforge, F. Harper, C. Dumont and A. Senik (2003) Cathepsin D triggers Bax activation, resulting in selective AIF relocation in $\mathrm{T}$ lymphocytes entering the early commitment phase to apoptosis. J. Biol. Chem. 278, 31401-31411.

22. Foghsgaard, L., D. Wissing, D. Mauch, U. Lademann, L. Bastholm, M. Boes, F. Elling, M. Leist and M. Jaattela (2001) Cathepsin B acts as a dominant execution protease in tumor cell apoptosis induced by tumor necrosis factor. J. Cell Biol. 153, 9991009.

23. Wang, K., X. M. Yin, D. T. Chao, C. L. Milliman and S. J. Korsmeyer (1996) BID: A novel BH3 domain-only death agonist. Genes Dev. 10, 2859-2869.

24. Zha, J., S. Weiler, K. J. Oh, M. C. Wei and S. J. Korsmeyer (2000) Posttranslational N-myristoylation of BID as a molecular switch for targeting mitochondria and apoptosis. Science 290, 1761-1765.

25. Korsmeyer, S. J., M. C. Wei, M. Saito, S. Weiler, K. J. Oh and P. H. Schlesinger (2000) Proapoptotic cascade activated BID, which oligomerizes BAK or BAX into pores that result in the release of cytochrome c. Cell Death Differ. 7, 1166-1173.

26. Gross, A., X. M. Yin, K. Wang, M. C. Wei, J. Jockel, C. Milliman and H. E. Bromage (1999) Caspase cleaved BID targets mitochondria and is required for cytochrome c release, while BCL-XL prevents this release but not tumor necrosis factor-R1/Fas death. J. Biol. Chem. 274, 1156-1163.
27. Li, H., H. Zhu, C. J. Xu and J. Yuan (1998) Cleavage of BID by caspase 8 mediates the mitochondrial damage in the Fas pathway of apoptosis. Cell 94, 491-501.

28. Chen, M., H. He, S. Zhan, S. Krajewski, J. C. Reed and R. A. Gottlieb (2001) Bid is cleaved by calpain to an active fragment in vitro and during myocardial ischemia/reperfusion. J. Biol. Chem. 276, 30724-30728.

29. Fields, S. (1989) A novel genetic system to detect protein-protein interactions. Nature 340, 245-246.

30. Takemoto, K., T. Nagai, A. Miyawaki and M. Miura (2003) Spatio-temporal activation of caspase revealed by indicator that is insensitive to environmental effects. J. Cell Biol. 160, 235-243.

31. Pei, Y., D. Xing, X. Gao, L. Liu and T. Chen (2007) Real-time monitoring full length Bid interacting with Bax during TNF- $\alpha-$ induced apoptosis. Apoptosis 12, 1681-1690.

32. Onuki, R., A. Nagasaki, H. Kawasaki, T. Baba, T. Q. Uyeda and K. Taira (2002) Confirmation by FRET in individual living cells of the absence of significant amyloid $\beta$-mediated caspase 8 activation. Proc. Natl Acad. Sci. USA 99, 14716-14721.

33. Wang, F., T. Chen and D. Xing (2005) Measuring dynamics of caspase-3 activity in living cells using fret technique during apoptosis induced by high fluence low power laser irradiation. Lasers Surg. Med. 36, 2-7.

34. Wu, Y., D. Xing, S. Luo, Y. Tang and Q. Chen (2006) Detection of caspase-3 activation in single cells by fluorescence resonance energy transfer during photodynamic therapy induced apoptosis. Cancer Lett. 235, 239-247.

35. Luo, Y., C. K. Chang and D. Kessel (1996) Rapid initiation of apoptosis by photodynamic therapy. Photochem. Photobiol. 63, $528-534$.

36. Rosenkranz, A. A., D. A. Jans and A. S. Sobolev (2000) Targeted intracellular delivery of photosensitizers to enhance photodynamic efficiency. Immunol. Cell Biol. 78, 452-464.

37. Wu, Y., D. Xing and W. R. Chen (2006) Single Cell FRET imaging for determination of pathway of tumor cell apoptosis induced by photofrin-PDT. Cell Cycle 5, 729-734.

38. Kessel, D., Y. Luo, P. Mathieu and J. J. Reiners Jr (2000) Determinants of the apoptotic response to lysosomal photodamage. Photochem. Photobiol. 71, 196-200.

39. Stoka, V., T. Boris, S. L. Schendel, T. H. Tim, T. Cirman, S. J. Snipas, L. M. Ellerby, D. Bredesen, H. Freeze and M. Abrahamson (2001) Lysosomal protease pathways to apoptosis cleavage of Bid, not pro-caspases, is the most likely route. J. Biol. Chem. 276, 3149-3157.

40. Cirman, T., K. Oresic, G. D. Mazovec, V. Turk, J. C. Reed, R. M. Myers, G. S. Salvesen and B. Turk (2004) Selective disruption of lysosomes in HeLa cells triggers apoptosis mediated by cleavage of Bid by multiple papain-like lysosomal cathepsins. J. Biol. Chem. 279, 3578-3587.

41. Boya, P., K. Andreau, D. Poncet, N. Zamzami, J. L. Perfettini, D. Metivier, D. M. Ojcius, M. Jäättelä and G. Kroemer (2003) Lysosomal membrane permeabilization induces cell death in a mitochondrion-dependent fashion. J. Exp. Med. 197, 1323-1334.

42. Houseweart, M. K., A. Vilaythong, X. M. Yin, B. Turk, J. L. Noebels and R. M. Myers (2003) Apoptosis caused by cathepsins does not require Bid signaling in an in vivo model of progressive myoclonus epilepsy (EPM1). Cell Death Differ. 10, $1329-1335$.

43. Caruso, J. A., P. A. Mathieu, A. Joiakim, H. Zhang and J. J. Reiners Jr (2006) Aryl hydrocarbon receptor modulation of tumor necrosis factor- $\alpha$-induced apoptosis and lysosomal disruption in a hepatoma model that is caspase-8-independent. J. Biol. Chem. 16, 10954-10967.

44. Miyawaki, A. (2003) Visualization of the spatial and temporal dynamics of intracellular signaling. Dev. Cell 4, 295-305.

45. Gao, X. J., T. S. Chen, D. Xing, F. Wang, Y. H. Pei and X. B. Wei (2006) Single cell analysis of PKC activation during proliferation and apoptosis induced by laser irradiation. J. Cell. Physiol. 206, 441-448. 